\title{
UN CUADRO INÉDITO DEL CRISTO DE BURGOS EN MÉXICO: EL DE JUAN DE VILLALOBOS DE LA PARROQUIA DE SAN PABLO APETATITLÁN (TLAXCALA)
}

\author{
AN UNPUBLISHED PAINTING OF THE CHRIST OF \\ BURGOS IN MEXICO: THE ONE OF JUAN DE VILLA \\ LOBOS AT SAN PABLO APETITLÁN'S PARISH CHURCH \\ (TLAXCALA) \\ LÁzaro Gila Medina \\ Universidad de Granada. España \\ lgila@ugr.es
}

Dos son los fines básicos de este artículo: primero, dar a conocer una nueva copia novohispana en pintura de la devota imagen del Cristo de Burgos, por fortuna, por no ser muy normal, firmada por su autor, el pintor tlaxcalteca Juan de Villalobos. Y como complemento oportuno, ofrecer noticias y datos conocidos y dispersos sobre él en distintas publicaciones para su mejor conocimiento.

Palabras clave: pintura novohispana; Barroco; Cristo de Burgos; Juan de Villalobos, siglo XVIII.

Two are the basic purposes of this paper. First provide a new novohispana painting copy of the devout image of Christ of Burgos, fortunately, not very regular, signed by its author, the Tlaxcalan painter Juan de Villalobos. And as timely supplement, provide news and known and scattered facts about him from different publications for better knowledge.

Keywords: Novohispanic painting; Baroque; Christ of Burgos; Juan de Villalobos, $18^{\text {th }}$ century.

\section{INTRODUCCION}

Con este trabajo damos a conocer una nueva pintura novohispana, totalmente desconocida, de la muy devota y célebre imagen castellana del Cristo de 
Burgos o de San Agustín'. Interesante lienzo firmado, aunque no fechado, por Juan de Villalobos, artista de muy aceptable calidad, activo fundamentalmente en el área de Puebla-Tlaxcala, aproximadamente, entre el último tercio del siglo XVII y el primero del siguiente.

Si es importante dar a conocer esta pintura, pues nos ratifica en la idea, tantas veces expuesta, de que la devoción a la venerada imagen del Cristo de Burgos tuvo gran arraigo y difusión en el virreinato de Nueva España, como se verá más adelante, igualmente es significativo el poder incluirla en el haber de Juan de Villalobos, pintor aún poco conocido y estudiado $\mathrm{y}$, en consecuencia, no muy valorado por la historiografía artística mexicana. Por eso, como colofón de esta contribución, incluimos y comentamos todas aquellas noticias biográficas, dispersas en las más dispares publicaciones, con la ilusión de que ayuden en un futuro próximo a realizar un trabajo lo más completo posible sobre esta importante y desconocida personalidad de la pintura novohispana del pleno barroco.

\section{BREVE RESEÑA HISTÓRICA DEL CRISTO DE BURGOS}

No obstante, como introducción oportuna e ilustrativa, ofrecemos una breve referencia histórico-artística de esta legendaria y singular advocación de Cristo, cuya imagen -madera recubierta con piel de vacuno- es una talla única y excepcional del gótico naturalista flamenco de mediados del siglo XIV (Figuras 1 y 2$)^{2}$. Sus rasgos distintivos, básicos y fundamentales, dejando al margen los

${ }^{1}$ Mi agradecimiento al Grupo de Investigación HUM 806 "Andalucía y América: Patrimonio y relaciones artísticas”, que dirige el Prof. Dr. D. Rafael López Guzmán, por la ayuda recibida para poder realizar este trabajo.

${ }^{2}$ La bibliografía sobre esta venerada imagen de origen agustino es muy numerosa, especialmente en los últimos tiempos. Incluso hoy disponemos de estudios generales con grandes horizontes geográficos. Es decir, intentando ofrecer una relación de todas las copias que se conservan tanto en España como Hispanoamérica y en Filipinas. Dos son los intentos más recientes; sin embargo, sospechamos que para elaborar la relación de obras o copias les ha servido de base o cualquier buscador de la red u otro medio como pueden ser las hemerotecas, siendo el trabajo de campo bastante pobre, por no decir nulo. Por tal motivo abundan numerosos errores y equivocaciones, $y$, en consecuencia, el rigor y la seriedad investigadora son limitados. El primero es de GARCÍA GUZMÁN, Miguel y GARCÍA REYES, Miguel Ramón: "Iconografía del Santo Cristo de Burgos o de San Agustín", Archivo Agustiniano, 205, 2003, pp. 261-306. Y el segundo es de ITURBE SAÍZ, Antonio: "El Cristo de Burgos o de San Agustín en España, Hispanoamérica y Filipinas", en CAMPOS Y FERNÁNDEZ DE SEVILLA, Francisco Javier (coord.): Actas del Simposium "Los crucificados, religiosidad, cofradías y arte". El Escorial, 2010, pp. 1-32. De ahí que, aunque a síntesis, en esta línea el estudio que estimamos más completo, serio y riguroso es el del sabio sacerdote burgalés, ya fallecido, LÓPEZ MARTÍNEZ, Nicolás: El Smo. Cristo de Burgos. Burgos, 1997. 
propiamente derivados de su configuración formal, son el faldellín, cuyo color cambia con la liturgia del día, y sobre todo los huevos de avestruz a los pies en un principio cinco y desde 1997 solo tres-. Ofrenda, según la leyenda, de un mercader norteafricano y de un profundo significado iconográfico e iconológico, pues el huevo es el símbolo de la vida y por ende de la Resurrección ${ }^{3}$. Por lo que esta escultura es la imagen más completa y profunda de un Crucificado, pues, si personifica el momento en que Cristo acaba de expirar - ya está muerto-, este atributo nos anticipa su victoria sobre la muerte con su Resurrección.

Lo cierto es que fue donada al monasterio burgalés de San Agustín -de ahí su otra advocación: la de Cristo de San Agustín- por un mercader burgalés a su regreso de Flandes y como gratitud hacia los religiosos agustinos. Pues gracias a sus oraciones, su viaje a estas lejanas tierras había trascurrido sin incidentes y con gran éxito económico y comercial.

Desde el punto de vista artístico, como se ha apuntado, la imagen es un ejemplo señero del gótico naturalista de mediados del siglo XIV; si bien en torno a ella se tejió una piadosa e interesada leyenda, que acabará por nublar la verdad histórica en aras a aureolarla, acrecentar su fama y popularidad como milagroso y, sobre todo, para que superase en antigüedad a la otra imagen también denominada también Cristo de Burgos -o de las Santas Gotas ${ }^{4}$ - que recibía culto en el convento de la Santísima Trinidad y desde la desamortización de Mendizábal (1836) en la vecina parroquia de San $\mathrm{Gil}^{5}$, aunque en la actualidad ni tiene faldellín, que cubría su hermoso y original paño de pureza lígneo, ni tampoco los huevos de avestruz (Figuras 3 y 4). Impresionante Crucificado, para unos italiano y para otros alemán, de finales del siglo XII o comienzos del siglo XIII, es decir, en la transición del románico al gótico, que le fue regalada, en Roma, por el papa Inocencio III a San Juan de Mata, su antiguo maestro, fundador de la orden trinitaria y del convento burgalés, en 1207, al que la regaló para su culto y veneración.

${ }^{3}$ COOPER, Jean C.: Diccionario de los símbolos. Barcelona, 2000, pp. 92-93.

${ }^{4}$ Esta advocación le viene de uno de los sucesos más sobresalientes que se le atribuyen. Tuvo lugar en 1366, durante la guerra fratricida entre Pedro I, rey legítimo de Castilla y León, y Enrique, su hermanastro, el futuro rey Enrique II. La capilla de la Magdalena del convento de la Santísima Trinidad, donde recibía culto la imagen del crucificado, por estar adosada a la muralla de la ciudad, facilitaba el acceso a la misma, de ahí que se mandara derribar. Mas, al iniciarse su demolición, un casquete de la bóveda hirió la cabeza del Cristo, saliendo de su herida 16 gotas de sangre, que fueron recogidas por una piadosa mujer, llamada María Jesús, que cuidaba la capilla y la imagen.

${ }^{5}$ La mejor y más completa monografía sobre este crucificado sigue siendo la de LÓPEZ GONZÁLEZ, Feliciano: Historia documentada y crítica de la Santa y Milagrosa Imagen de Jesús Crucificado que con el título de Santísimo Cristo de Burgos se venera en la Iglesia Parroquial de San Gil de la ciudad expresada. Salamanca, 1907. Mientras que para su actual capilla e historia: MUGA, Pedro y REVENGA, Heliodoro: La iglesia de San Gil Abad. Burgos, 2011, pp. 41-47. 
Así pues, el Cristo de la Trinidad es anterior en el tiempo al de San Agustín , como igualmente el cenobio trinitario lo es al convento de San Agustín, instituido en 1287. Sin embargo, el prestigio y autoridad del monasterio agustino y sobre todo de su famoso Crucificado sería aún mucho mayor si su antigüedad hundiera sus raíces en los momentos iniciales del cristianismo. Para ello se inventa un devoto e interesado relato, que al fin y a la postre acabará por imponerse y ser aceptado. La cuidadosa y motivada versión, muy escuetamente, arranca atribuyendo su hechura nada más y nada menos que al mismo Nicodemo -uno de los que ayudó a bajar a Cristo de la cruz-, quien la guardó y veneró con enorme celo y piedad todos los días de su vida. Tras él, por herencia familiar, pasó a Beirut (Líbano), donde sería incluso profanada en 765, de nuevo por los judíos. Por último, en 1187, al ser conquistada la ciudad por Saladino, sus dueños, para evitar su profanación, la meten en una caja de cristal, ésta a su vez en otra de madera, y la echan al mar en la confianza de que cayera en manos de buenas personas que cuidarán de ella ${ }^{7}$ Y así felizmente acaeció, pues cuando la caravana comercial burgalesa volvía de Flandes a Santander, la halló flotando en el Cantábrico, quedando todos impresionados al ver la imagen del Crucificado, especialmente el mercader, quien, recordando la promesa hecha a los agustinos, logra hacerse con ella para cumplir con la palabra dada.

En definitiva, historia y leyenda caminan por senderos distintos, o, a lo más, como sucede en este caso, se entrelazan según convenga para darle visos de credibilidad $^{8}$. Mas al margen de estas cuestiones, lo evidente es que ya desde mediados

${ }^{6}$ A fin de distinguirlos en las ilustraciones, los llamaremos con sus antiguas denominaciones populares: Cristo de Burgos de San Agustín y Cristo de Burgos de la Trinidad, en alusión a los conventos donde residían y recibían culto con anterioridad a la desamortización de Álvarez Mendizábal. Incluso, las ilustraciones que ofrecemos del primero son anteriores a 1997, año en que la imagen de la catedral fue objeto de una agresiva restauración que ha desfigurado su conformación visual secular.

7 DE LA VORÁGINE, Santiago: La Leyenda Dorada. T. II. Madrid, 1982, pp. 585-590.

8 A este respecto fueron claves la obra del religioso agustino LOVIANO, Pedro: Historia y milagros del Ssmo. Christo de Burgos. Burgos, 1760, pp. $24-62$ ( $1^{\mathrm{a}}$ ed., Madrid, 1740). Más interés tiene el padre Enrique Flórez, pues siendo un gran historiador riguroso y serio, sin embargo, como burgalés y fraile agustino, admite las interesadas leyendas como ciertas y verídicas. FLÓREZ, Enrique: España Sagrada. T. XXVI (Contiene las iglesias colegiales, monasterios y santos de la diócesis de Burgos. Conventos, parroquias y hospitales de la Ciudad). Madrid, 1772, pp. 495-522. Si bien, en última instancia, debemos concluir advirtiendo que, tanto el uno como el otro, tienen un precedente bibliográfico muy importante que les sirve de referencia, pues le siguen literalmente. Se trata de la obra anónima Miraglos del Sto. Cruçifixo. Códice 38 de la biblioteca de la catedral de Burgos. Burgos, 1574. Hay una segunda edición también burgalesa, por el impresor Juan Baptista Verasio, 1604. Incluso otra tercera edición, igualmente de la misma procedencia, por Pedro Hudobro, 1623. Precisamente es en el capítulo III, muy elocuentemente titulado "De 
del siglo XIV el Santo Cristo de Burgos de San Agustín gozó, y lo sigue teniendo hasta el día de hoy, del fervor y de la devoción a todos los niveles y grupos sociales, no solamente en España sino también al otro lado del Atlántico, en las Filipinas, e, incluso, hemos podido rastrear su presencia en los dominios que fueron españoles en el sur de Italia, superando con creces al Cristo de la Trinidad. Muchas razones se pueden aducir, mas, en este momento solo señalaremos dos: en primer lugar, los agustinos, constituidos como orden conventual a mediados del siglo XIII, tuvieron una mayor expansión y difusión geográfica, muy superior a los trinitarios, cuya misión fundamental era la de redimir cautivos en tierras de infieles, y sobre todo el poder persuasivo del Crucificado agustino, que casi llega al hiperrealismo al reflejar con toda crudeza en su anatomía la tragedia y el drama de su pasión, por lo que despierta inmediatamente, con profunda eficacia y firmeza en el fiel creyente, los más nobles sentimientos de lástima, piedad y compasión, a lo que ayuda su misma configuración formal, al estar totalmente articulado y llevar incluso bajo la llaga del costado derecho un dispositivo interno para almacenar sangre y así en el momento de la ceremonia del descendimiento de la cruz conseguir un mayor realismo y eficacia ${ }^{9}$. Si bien la imagen agustina jamás procesionó y en consecuencia se pudo celebrar tal ceremonia litúrgica -recientemente, en 2014, el cabildo catedralicio burgalés ha hecho una réplica de la talla original, con su correspondiente trono, habiéndosele encomendado su procesión el Viernes Santo y posterior descendimiento de la cruz a la Hermandad de las Siete Palabras-.

De ahí que, en su capilla claustral del citado convento burgalés y, desde la Desamortización de Mendizábal, concretamente desde finales de enero de 1836, en la primera capilla de la derecha de la catedral de Burgos, ya desde mediados del siglo XIV haya recibido multitud de visitantes y devotos. A sus pies se postraron desde los peregrinos que iban a Santiago de Compostela-Burgos es un hito importante en el camino francés- hasta los más importantes personajes del momento, ya desde la baja Edad Media, como Santa Úrsula de Suecia, los Reyes Católicos, el Gran Capitán o la misma Santa Teresa de Jesús, cuya contemplación le causó una profunda impresión ${ }^{10}$-fue el 26 de enero de 1582 cuando se dirigía, ya

como la Santa Imagen del Santo Crucifixo de Burgos fue hecha por Nicodemus, discípulo de Christo, Nuestro Señor" (pp. 4-7), donde se identifica el Cristo de Burgos de San Agustín con el realizado por José de Nicodemo.

${ }^{9}$ Sobre este detalle véase MARTÍNEZ MARTÍNEZ, María José: "El Santo Cristo de Burgos. Contribución al estudio de los crucificados articulados españoles", Boletín del Seminario de Arte y Arqueología, 69, 2003, pp. 207-246.

${ }^{10}$ Sobre la fundación burgalesa y el relato de la impresión que le causó la contemplación del Cristo de Burgos, que fue lo primero que hizo al entrar a Burgos, véase DE LA FUENTE, Vicente: Escritos de Santa Teresa de Jesús. Añadidos e ilustrados por. Madrid, 1877 , p. 243. 
muy enferma, a Burgos, a fundar el que sería su último convento, pues falleció en octubre de ese mismo año, concretamente el 4 de octubre-.

Al mismo tiempo, sus muchos fervorosos devotos e incondicionales seguidores, agradecidos e impresionados por los auxilios y favores recibidos, propagaron su devoción y culto por toda España, bien de forma individual o a través de asociaciones religiosas, de derecho canónico, tales como cofradías y hermandades. En esta labor propagadora y divulgadora también ocuparon un papel clave los mismos religiosos agustinos. Pues pronto adoptaron y convirtieron al Crucificado burgalés en una advocación propia y universal para toda la orden, si bien preferirán la advocación de Cristo de San Agustín, mientras que el personal civil optará por la de Cristo de Burgos, la mayoritaria y la que con el tiempo se impondrá -como caso ilustrativo señalaremos que en 1740 el agustino fray Pedro Loviano publica su primera gran monografía, intitulándola Historia y milagros del Ssmo. Christo de Burgos ${ }^{11}$-. En definitiva, la experiencia nos dice que el título o advocación de Cristo de San Agustín ni es tan frecuente ni está tan generalizada como la de Santo Cristo de Burgos -incluso hubo ciudades donde convivieron las dos advocaciones, como fueron los casos de Sevilla y Granada-.

\section{EL CRISTO DE BURGOS O DE SAN AGUSTIN EN NUEVA ESPAÑA}

Necesariamente, debemos comenzar advirtiendo que, por fortuna, en los últimos años, los estudios y publicaciones sobre el arraigo popular y el alcance geográfico que alcanzaron las principales advocaciones y devociones españolas, especialmente las de Cristo y María, que cruzaron el Atlántico, cada vez son más numerosos, profundos y amplios ${ }^{12}$. Del mismo modo, una vez que florezcan y afiancen en aquellos territorios de ultramar nuevas devociones, se producirá el fenómeno inverso. Muchos ejemplos podríamos traer a colación en el primero de los casos; mas, sin duda alguna, dos de los más emblemáticos pueden ser el de la piadosa imagen de la Soledad de Madrid ${ }^{13}$ y el Cristo de Burgos o de San Agustín, ambas esculturas.

${ }^{11}$ Madrid, Imprenta del Venerable Padre Fray Alonso de Orozco, 1740. Una segunda edición se haría en Burgos, en la imprenta de la Santa Iglesia Catedral, en 1760.

${ }^{12}$ RICARD, Roberto: La conquista espiritual de México. Ensayo sobre el apostolado y los métodos misioneros de las órdenes mendicantes en la Nueva España de 1523-1524 a 1572. México, 1995. Concretamente el capítulo IV, "El esplendor del culto y la devoción”, pp. 282-304.

${ }^{13}$ Igualmente la bibliografía sobre la Soledad de Madrid es copiosísima. Pero como trabajos recientes rigurosos y serios recomendamos SÁNCHEZ DE MADARIAGA, Elena: "La Virgen de la Soledad. La difusión de un culto en el Madrid Barroco", en La imagen religiosa en la monarquía hispánica. Usos y espacios. Madrid, 2008, pp. 219-241. 
La primera fue una imagen de vestir, realizada por Gaspar Becerra, en 1565, y por encargo de Isabel de Valois, tercera esposa de Felipe II, para el convento de los mínimos de la Victoria de Madrid, y la segunda, como hemos anticipado, el Cristo de Burgos o de San Agustín, que recibía culto en el convento de San Agustín de Burgos y, desde enero de 1836, en su catedral metropolitana. Mientras que en el segundo supuesto, es decir, en el de las devociones que vienen de allende a España, se lleva la palma por excelencia y con mucha diferencia la Virgen de Guadalupe, dentro de las marianas, mientras que en las de Cristo no hay tanta claridad y contundencia, si bien fueron muy habituales el Señor de Chalma, un hermoso Crucificado que se venera en esta localidad próxima a Malinalco, y mucho más aún el Nazareno del hospital de Jesús de Ciudad de México -tal fama y popularidad por sus dotes taumatúrgicas fue adquiriendo a partir de mediados del siglo XVII este Nazareno en una de sus caídas, que, con el tiempo, este hospital fundado por el mismo Hernán Cortés con el nombre de la Limpia Concepción, pasaría a llamarse de Jesús, pasando la advocación mariana a segundo lugar-.

En el caso de las devociones de origen español, por representar dos momentos claves de la Pasión de Cristo: su Crucifixión y la Soledad de María en el calvario, tras haberle dado sepultura, calaron en lo más profundo de la sensibilidad popular y pronto se difundieron muy ampliamente. Normalmente, lo solicitado y añorado por sus devotos era una copia en escultura y especialmente en pintura, los más pudientes económicamente, pues la gente humilde se conformaba con su estampa. Reproducciones, más o menos fidedigna del original, donde en la mayoría de las ocasiones los valores y la calidad artística no eran el principal objetivo, pues para el devoto-comitente, salvo espíritus muy selectos y con una solvente capacidad económica que le permitiera pagar a un buen artista, lo importante era el tener y gozar de un trasunto lo más fiel posible de esa entrañable imagen de su especial devoción y cariño para orar ante ella y encomendarse en momentos de dificultad -trampantojos a lo divino las denominó muy acertadamente Alfonso E. Pérez Sánchez ${ }^{14}$-. Su demanda fue en aumento con el tiempo, bien para los oratorios particulares, capillas funerarias, o para asociaciones piadosas como hermandades y cofradías, viéndose potenciado en ambos casos además, no lo olvidemos, por tener la facultad de despertar en su devoto sus más profundos sentimientos religiosos y por el carácter taumatúrgico que las envolvía, lo que acrecentaba su fama. Si esto es una hermosa y fecunda realidad para España, también lo es para los antiguos territorios de ultramar, y no solo al otro lado del Atlántico, sino también para Filipinas.

Más reciente y sumamente interesante es el de FERNÁNDEZ MERINO, Eduardo: La Virgen de luto. Indumentaria de las dolorosas castellanas. Madrid, 2012, pp. 21-46.

${ }^{14}$ PÉREZ SÁNCHEZ, Alfonso E.: "Trampantojos a los divino", Lecturas de Historia del Arte, III, 1994, pp. 139-155. 
En el caso concreto del Cristo burgalés la difusión de la devoción tuvo dos grandes agentes difusores y propagadores: por un lado, los burgaleses y también los cántabros, y, en general, sus muchos devotos de origen español al margen de su origen geográfico, quienes lo harán con la advocación de Burgos. En segundo lugar, los frailes agustinos, quienes ${ }^{15}$, aunque les sea más familiar y entrañable la de Cristo de San Agustín, pronto ceden ante la topográfica, si bien, en última instancia, se impondrá y generalizará la de "El Señor de Burgos".

Por lo que respecta a Nueva España, incluyendo aquí la capitanía general de Guatemala, aún hoy día en muchos lugares se le profesa una gran devoción tanto a nivel particular como colectivo, aunque en este segundo caso sin estar sus fieles devotos asociados en cofradías o hermandades canónicamente formalizadas. Es verdad que antaño fueron muy numerosas, si bien, por diversas causas, se han ido perdiendo en las últimas centurias, permaneciendo hasta hoy la imagen de su titular. Así acontece en Ciudad de México ${ }^{16}$, en Puebla de los Ángeles, en distintos lugares del estado de México, Hidalgo o Tlaxcala, donde hay numerosas copias sueltas o en retablos, de una rica y variada iconografía, como es el cuadro que nos ocupa.

${ }^{15}$ Por lo que respecta a Andalucía la devoción al Cristo alcanzaría un gran auge, y aún se mantiene en Sevilla, donde curiosamente se veneraría, y aún sigue vigente, bajo las dos advocaciones de Burgos o de San Agustín, siendo pues un punto de referencia clave para su difusión por Andalucía Occidental. Mientras que para Andalucía Oriental y el ámbito castellano-manchego lo sería la llegada accidental, en 1637, a la pequeña villa jiennense de Cabra de una copia en pintura - popularmente conocida como Cristo de Cabrilla-, que el noble burgalés don Jerónimo de Sanvítores y de la Portilla trasladaba con todas sus pertenencias a Guadix, donde había sido nombrado corregidor. Tras obrar varios hechos, considerados por la autoridad eclesiástica del momento como sobrenaturales, el cuadro quedará en esta pequeña localidad, convirtiéndose en palabras del arzobispo de Toledo y primado de España, cardenal don Baltasar de Moscoso y Sandoval, "en uno de los santuarios más famosos de España y consuelo de las Andalucías". Sobre la advocación de Cristo de Cabrilla véase GILA MEDINA, Lázaro: Cabra del Santo Cristo (Jaén). Arte, Historia y el Cristo de Burgos. Granada, 2002.

${ }^{16}$ Una de las más tempranas cofradías al Cristo de Burgos surgió en el antiguo convento agustino de Culhuacán, concretamente en 1629. Sin embargo, con el tiempo la más importante y poderosa sería la de los cántabros, fundada a finales del siglo XVIII. Tenían capilla propia en el desaparecido atrio del convento casa grande de Ciudad de México. IGLESIAS GÓMEZ, Ángel: Los cántabros y su Cristo de Burgos en Nueva España. La cofradía de Culhuacán. Ciudad de México, 1999. Para la capilla de los cántabros, también consagrada a la Inmaculada Concepción, véase SALAZAR, Nuria: La capilla del Santo Cristo de Burgos en el ex Convento de San Francisco. Ciudad de México, 1999. Sin embargo, el trabajo más completo, pues estudia los dos siglos de historia de la Hermandad de los Cántabros, es el de ÁVALOS SANTIAGO, Ana E.: La cofradía del Santísimo Cristo de Burgos 1774-1861. Ciudad de México, 1995. En realidad fue su trabajo para obtener la maestría en Historia, siendo su directora Martha Raquel Fernández García. 
Mas, realmente, las tres grandes ciudades mexicanas donde el Señor de Burgos tiene su santuario o una gran capilla aneja a un concurrido templo y aún pervive con gran fuerza y extensión su culto y devoción son San Luis Potosí, donde popularmente se le conoce también como el Señor del Saucito ${ }^{17}$-por el material base de la talla-, recibiendo culto en un templo de factura relativamente reciente; en Guanajuato, concretamente en una hermosa capilla lateral de la iglesia de San Pedro de Alcántara del antiguo convento de San Diego de Alcalá, de franciscanos descalzos $^{18}$; y en Ciudad Jiménez, en el estado de Chihuahua, aquí es el patrón de la ciudad y el titular de su iglesia parroquial por lo que preside su capilla mayor, siendo curiosamente una imagen pétrea.

\section{ESTUDIO DEL CUADRO}

La localidad de San Pablo de Apetatitlán de Antonio Carvajal, que es el nombre completo de este municipio, muy próximo a la ciudad de Tlaxcala, hasta el punto que ya casi está conurbado con ella, debe su fundación y desarrollo urbano, económico y de población a esa serie de lugares que fueron surgiendo, ya desde la primera mitad del siglo XVI, en el importantísimo Camino Real que iba desde Veracruz hasta la Ciudad de México a fin de facilitar la laboriosa y agotadora travesía a esa multitud de viajeros, comerciantes, etc., que por él transitaban, especialmente los españoles y mercancías que arribaban desde la metrópoli a Veracruz con la flota de Indias - esta misma causa sería la razón de ser de la fundación de Puebla de los Ángeles, en 1531-.

Con una planimetría ortogonal, aquí también, una vez más, los franciscanos, es decir, el clero regular, están presentes desde sus comienzos, haciéndose cargo no solo de la atención espiritual de sus primeros moradores sino colaborando en la puesta en marcha de todas las instituciones y actividades necesarias y complementarias para el normal desenvolvimiento de la vida ciudadana del aquel pequeño lugar. No obstante, pronto, a comienzos del siglo XVII, la parroquia sería secularizada, es decir, se pondría bajo el control del clero secular, por lo que la huella y los testimonios franciscanos que han pervivido son bastante escasos.

Igualmente, como es lo normal, uno de los lados de su popular plaza mayor, concretamente el flanco sur, se destina a los edificios religiosos, en este caso la parroquia de San Pablo, servida en la actualidad por dos templos con su aneja casa cural (Figura 5). De esas dos iglesias, que componen su única parroquia, la construcción más antigua, puesta, lógicamente, bajo la advocación del Apóstol de los

${ }^{17}$ MONTEJANO Y AGUIÑAGA, Rafael: El Señor del Saucito y su templo. San Luis Potosí, 1972 (2. ed., San Luis Potosí, 2009).

18 SERRANO ESPINOZA, Luis: San Diego. El templo conventual de San Pedro de Alcántara. Guanajuato, 2002, pp. 285-333. Precisamente fue este autor el que nos puso en la pista del lienzo de Juan de Villalobos de San Pablo de Apetatitlán. 
Gentiles, es un templo de medianas proporciones y con una planta de cruz latina. Su edificación se debió de materializar en las décadas a caballo entre los siglos XVI y XVII y a iniciativa de los franciscanos, destacando de entre sus bienes muebles, su retablo mayor, una obra ya del pleno Barroco.

Con su crecimiento urbano y de población de esta pequeña localidad, fruto, como se dijo, de su estratégica posición geográfica en esa importante arteria de comunicaciones que fue el Camino Real de Veracruz a Ciudad de México, hay que añadir ahora, además, su conversión en un punto clave y necesario entre los distintos caminos que unían la ciudad de Tlaxcala con esos otros nuevos pueblos y localidades más alejados y distantes de la misma. Este aumento de población ocasionó, muy a finales del siglo XVIII, la construcción de un nuevo templo, paredaño, aunque en ángulo recto con el primitivo, también una planta de cruz latina, de mayores dimensiones y de no muy acertada factura neoclásica.

Esta singularidad de ser una sola parroquia servida por dos templos contiguos, estuvo complementada y potenciada por la posesión de un importante patrimonio de bienes muebles, formado básicamente por retablos, esculturas, cajoneras, espejos, mesas de altar, ornamentos religiosos y muy especialmente pinturas. Importante acervo patrimonial que fue objeto de un atroz robo, nunca esclarecido, acaecido a finales de la pasada centuria. No obstante, aún quedó bastante, especialmente esculturas, pinturas, ornamentos y espejos, que los sacerdotes encargados de la parroquia, especialmente don Antonio Ordóñez Ahuactzin $^{19}$, su cura-párroco ya durante bastantes años, retiraron del culto y guardan celosamente en distintas salas de la casa cural, adaptadas a museo parroquial. Actitud muy loable, si bien hay cierto desorden en el montaje y colocación de las piezas, cuyo estado de conservación, en su mayor parte, no es el más deseable y, en consecuencia, están necesitadas de una intervención. Restauración que, sin la ayuda exterior, bien oficial o particular, no se podrá llevar a cabo, dado que las posibilidades económicas de esta parroquia son muy limitadas y además su clero parroquial tiene que acudir a solventar otros muchos frentes ajenos al patrimonio cultural y, sin duda, dentro de su organigrama, de más prioridad.

Precisamente la pintura que nos ocupa del Cristo de Burgos fue una de las que se salvó del robo, quizás debido a sus grandes dimensiones, concretamente 230 x 152,5 cm (Figuras 7, 8 y 9). No obstante, sabemos que el lienzo fue desmontado del bastidor, se dobló varias veces para facilitar su posible trasporte, aunque, en última instancia, los ladrones lo dejaron abandonado en el templo más antiguo. Así doblado -y es algo que se observa a primera vista- permaneció algunos años, con el daño tan tremendo que sufrió la pintura, hasta que el actual párroco,

${ }^{19}$ Mi más sincera gratitud a don Antonio Ordóñez, párroco de este municipio, por la amabilidad y generosidad con que nos trató tanto a mí como al Dr. Luis J. Cuesta Hernández, de la Universidad Iberoamericana de Ciudad de México, en nuestra visita a esa localidad el sábado 29 de mayo de 2015. 
el ya citado don Antonio Ordóñez Ahuactzin, al comprobar que estaba firmado, que ofrecía interés artístico y por la extraña iconografía del Crucificado representado, lo ha fijado de nuevo a un bastidor, lo ha adaptado a un antiguo marco de madera en su color y lo ha colocado presidiendo el despacho parroquial para una mayor salvaguarda del mismo.

Esta compleja y accidentada historia de la pintura se ve complementada por su extraordinaria riqueza iconográfica y por su singular calidad artística. Es cierto que en las representaciones pictóricas de la venerada y devota escultura del Cristo de Burgos no existe un patrón único. Lo normal es que sobre un fondo totalmente neutro aparezca el Cristo de Burgos con su faldellín blanco y los huevos de avestruz a los pies, resaltándose así sus valores escultóricos. En algunos casos, para simular que está en su altar de culto, se le colocan a un lado y otro unos candeleros con sus velas encendidas, incluso jarrones con flores, del techo penden unos cortinajes, que se abren para enmarcarlo y enaltecerlo, e incluso también en algunas ocasionen unas lámparas votivas. Mas será a los pies de la imagen, que simula estar sobre un montículo en recuerdo del Gólgota, donde nos podemos encontrar diversos motivos iconográficos específicos, aparte de los citados huevos de avestruz, su símbolo iconográfico por excelencia, tales como la calavera -en alusión a Cristo vencedor de la muerte y a que en el Gólgota se enterró Adán-, la serpiente -como se disfrazó Satanás para tentar a Adán y Eva en el Paraíso Terrenal-, una corona de espinas -en recuerdo a la que le regaló el Gran Capitán para cumplir la promesa hecha al verse en un gran aprieto en la Guerra de Granada y salir airoso del mismo-, etc.

En algunos casos, ciertamente muy pocos, la pintura conforma un Calvario completo al figurar junto al Cristo de Burgos, la Virgen María a su derecha, el apóstol San Juan a su izquierda y la Magdalena de rodillas a los pies. Mas, en esta ocasión, la Virgen María, ha sido sustituida por San Juan Evangelista y, en el lugar que tradicionalmente él ocupa, aparece María Magdalena.

Probablemente, esta manera tan original de componer la escena del supuesto Calvario y los personajes, que en él aparecen, sería una imposición del comitente que le encargara la pintura a Juan de Villalobos. Sea lo que fuere, lo que nos interesa es la nobleza de la figura del Cristo de Burgos, colocado sobre cruz arbórea, con remates argénteos en sus extremos, el faldellín blanco -es el color predominantes en los copias del Cristo de Burgos en clara alusión al Domingo de Resurrección o Dominica in albis-, muy bien plisado y enriquecido en su parte inferior con una delicada franja de exquisitos motivos ornamentales geométricos.

Aquí, en este pequeño detalle, que quizás pase inadvertido, tenemos otra de las notas específicas de esta pintura, pues lo normal es que el faldellín se complete en su parte inferior con una rica cenefa de encaje de puntillas añadida al mismo. Tira ornamental que aquí se ha suprimido y se ha reemplazado por esa orla de adornos geométricos desarrollados en la misma tela del faldellín y no añadida en su parte inferior. 
Con toda probabilidad Juan de Villalobos tuvo que tener delante alguna estampa o grabado del Cristo de Burgos, tan abundantes en Nueva España, que le serviría de fuente de inspiración, pues la reproducción está bastante bien lograda. Incluso, junto a esta fuente particular para la imagen del Cristo de Burgos, otra estampa le ayudaría a componer su singular Calvario con San Juan y la Magdalena, probablemente flamenca por sus generosas anatomías y amplitud de los ropajes de San Juan y la Magdalena. A este respecto pensamos que la de Bolswert Schelte Adamsz sobre composición de Jacob Jordaen, de 1611, titulada Crucifixión de Cristo con la Virgen, San Juan, la Magdalena y otras figuras no andaría muy lejana. En la fuente gráfica, San Juan de pie se sitúa a la derecha del Crucificado y, en el lado opuesto, María -en un Calvario canónico es al revés-, y a los pies, la Magdalena y otros personajes. Nuestro artista, con buen criterio, simplificó la composición planteándola con el Cristo de Burgos, en el centro, a su derecha San Juan y en el otro ha cambiado la Virgen María por Santa María Magdalena.

En definitiva, se trata de un trabajo muy bien planteado y resuelto, dentro de la sencillez y la claridad compositiva. La noble y monumental figura del Cristo de Burgos, de un exquisito y ajustado dibujo y sobre una cruz arbórea, centra la escena. Juan de Villalobos ha puesto todo su empeño en modular con todo detalle la anatomía del cuerpo, marcando con numerosos y exagerados hematomas las huellas que los castigos previos al momento del Calvario habían dejado en el cuerpo. Mas, donde se aleja bastante del original burgalés es en su rostro, de una gran emoción y dulzura, totalmente alejada de la tensión y dramatismo que caracterizan al original castellano, cuyo realismo es tan sorprendente que algunos le han comparado con el rostro del cadáver de un hombre que acaba de fallecer.

San Juan Evangelista, a su derecha, es también muy original. En actitud de caminar y ligeramente escorado a su izquierda para así mirar con más intimidad a Cristo, eleva su triste y apenado rostro, para intentar dialogar con él, lo que ya no es posible pues Cristo acaba de expirar. Con amplia túnica, de un intenso verde, y manto rojo que le cubre los hombros y lo recoge en el brazo derecho, cuya mano se lleva al corazón y extiende la otra, buscando acentuar la teatralidad e insistir en drama sacro que se está representado y viviendo.

La actitud gesticulante del apóstol San Juan se torna en la Magdalena en recato, modestia y mesura. Igualmente de pie, y ligeramente vuelta a su derecha para ver a Cristo, inclina su cabeza, de bellísimo rostro de finas facciones, como intentando contener su dolor. Con su mano derecha se limpia las lágrimas de los ojos, mientras con la otra sujeta el tarro de los ungüentos que se han de usar en el momento previo a darle sepultura. De amplias y voluminosas vestiduras, de delicioso colorido, complementan a las de San Juan, su túnica violácea y manto ocre, la trasparencia del blanco del velo, que le envuelve el cuello, es realmente un ejemplo de su calidad pictórica, precisamente a sus pies y ya en el ángulo inferior 
derecho del cuadro, aparece el nombre del pintor "Ju. de Villalobos. F[eci]t" (Figura 6).

\section{DATOS Y NOTICIAS PARA SU BIOGRAFÍA}

Finalmente, ofrecemos una aproximación a su perfil biográfico a pesar de que aún es bastante pobre y limitado, al igual que sucede con la mayoría de los pintores que trabajaron en el territorio de Puebla y Tlaxcala. Ciudades muy próximas entre sí y centros artísticos de bastante significación en la época del virreinato y durante el Barroco, especialmente Puebla, la segunda ciudad en importancia artística después de la capital. Así pues, aquí reunimos y ofrecemos una serie de datos y noticias dadas a conocer por varios autores y en distintas publicaciones ${ }^{20}$.

Sabemos que Juan de Villalobos era poblano de nacimiento, aunque ignoramos la fecha exacta de su venida al mundo, y aquí desarrolló su actividad profesional alcanzando también a las ciudades más próximas, como es el caso que nos ocupa. El primer dato cierto es su fecha de casamiento con Micaela Ruiz, celebrado el 8 de diciembre de 1687 en la parroquia poblana de San José, actuando como testigo el pintor Juan Tinoco, sin duda su maestro ${ }^{21}$. Partida de matrimonio que nos aclara que era soltero español, es decir, que no era de ascendencia indígena mexicana, natural y vecino de Puebla, de oficio pintor e hijo de padres no conocidos, por lo que se crió en la casa del capitán Gaspar López Torrija, hermano del doctor y maestro Carlos López Torrija, sacerdote que oficio dicho matrimonio.

La siguiente noticia significativa acontece en 1698, once años después de su boda, concretamente el 20 de junio, cuando nos lo encontramos tasando las pinturas del licenciado Antonio de Linares. 60 pinturas en total y todas ellas

${ }^{20}$ Lamentablemente no existe un trabajo reciente y dedicado en exclusiva a este artista en cuestión. Los datos y noticias que conocemos aparecen en publicaciones de conjunto y de cierta antigüedad. De ahí que solo señalaremos aquellas que consideramos más importantes y originales. OLIVARES IRIARTE, Bernardo: Apuntes artísticos sobre a historia de la pintura en la Ciudad de Puebla. Ciudad de México, 1911. Más interés presenta PÉREZ DE SALAZAR Y HARO, Francisco José: Algunos datos sobre la pintura en Puebla en la época colonial. Ciudad de México, 1923. El texto fue incorporado a otra obra más amplia por VARGASLUGO RANGEL, Elisa: Historia de la pintura en Puebla. México, 2003. Gran interés ofrece el gran historiador del arte mexicano TOUSSAINT, M.: Arte colonial en México. Ciudad de México, 1990 ( $1^{\mathrm{a}}$ ed., 1948), y muy especialmente Pintura colonial en México. Ciudad de México, 1990 ( $1^{\mathrm{a}}$ ed., 1965). Aunque, en definitiva, el más completo repertorio bibliográfico sobre arte novohispano aún sigue siendo el de VICTORIA, José Guadalupe: Una bibliografía de arte novohispano. Ciudad de México, 1995.

${ }^{21}$ Sobre este pintor véase RODRÍGUEZ MIAJA, Fernando: Una cuestión de matices. Vida y obra de Juan Tinoco. Ciudad de México, 1996. Precisamente en esta obra, en la p. 412, se nos dan numerosas noticias de Juan de Villalobos. 
anónimas, destacan por su origen "18 países" - paisajes- flamencos. Información ésta nada baladí, pues nos confirma en primer lugar que la importación y presencia de pinturas de origen flamenco era querida y demandada en aquellos territorios y sus pobladores mejor situados económicamente y, en segundo lugar, que Juan de Villalobos dentro de su medio socio-laboral ya sería un profesional valioso y respetado cuando se le encarga este cometido tan delicado como es la valoración de unas pinturas, lo que exige una gran preparación especial y solvencia profesional e intelectual.

En 1723 fecha uno de sus encargos de mayo envergadura: el magno conjunto mariano del camarín del santuario de Nuestra Señora de Ocotlán ${ }^{22}$, en las proximidades de Tlaxcala. Son siete lienzos de grandes dimensiones -320 x $235 \mathrm{~cm}$, excepto la Coronación de la Virgen situado encima de la puerta acceso al mismo-, cuya ejecución, por la amplitud del trabajo, la iniciaría algún tiempo antes. Finalmente, su fallecimiento se produjo en Puebla en 1724, concretamente el 4 de julio.

Otros dos ciclos pictóricos importantes en la misma ciudad de Puebla de los Ángeles, serían el que adorna las sacristías de la iglesia de la Compañía de Jesús y la del convento de San Francisco, así como también dos grandes lienzos en la iglesia del Sagrario, aneja a la catedral angelopolitana. Fuera de la ciudad, pero en localidades muy cercanas a la misma, tenemos las pinturas del presbiterio de la iglesia del antiguo convento de Santa María Magdalena en San Martín de Texmelucan de la Bastida y las consagradas a la Pasión de Cristo del retablo del crucero de la iglesia parroquial de Nopalucan.

Por último, hay dos facetas en la actividad profesional de Juan de Villalobos que no han sido valoradas suficientemente. Nos referimos a su actividad como solicitado retratista y como decorador de los tubos de los grandes órganos de las iglesias del entorno Puebla-Tlaxcala. En el primero de los casos, generalmente, son retratos de monjas coronadas, es decir, se representa en el momento en que la novicia, después de varios años de prueba en el convento, realiza sus votos solemnes, uniéndose ya para siempre a la comunidad de religiosas como leal y fiel esposa de Cristo. En este caso el interés de la pintura es doble, pues si por un lado la familia de la religiosa encarga la obra para tener recuerdo gráfico para la posteridad de ese solemne momento tan transcendental para la religiosa, de otro lado también nos ayuda a conocer el vestuario y toda la parafernalia de elementos y símbolos que envolvía a dicho acto. Uno de sus retratos más originales es el de madre María de Guadalupe, acompañada de Santa Bárbara y fechado en 1723, justo un año antes de su fallecimiento. La religiosa aparece lujosamente vestida, como una novia de bastantes posibilidades económicas, aunque en esencia es el hábito de las dominicas. Se cubre la cabeza con un alto copete floral, coronado

22 ÁVILA, Mariana: "Obras de Juan de Villalobos bajo celeste protección, los siete óleos del camarín de Ntra. Sra. de Ocotlán”, El Universal, México, 28-5-2000, pp. 7-10. http://www.eluniversal.com.mex/cultura/4436.html. 
por la paloma del Espíritu Santo, en su mano izquierda una hermosa vela envuelta en vistosas flores, lo que es bastante normal, pues es el símbolo de que su fe en Cristo siempre debe estar despierta, mientras da la otra a Santa Bárbara, su protectora, por la que debió sentir una especial devoción. Representada como un encantadora joven, con un ostensorio en sus manos, envuelta en un minucioso paisaje, en cuya lontananza se observa una esbelta torre, su atributo iconográfico más importante, pues aquí estuvo encerrada y fue mandada martirizar por su progenitor. No es normal la presencia de algún santo o santa en los retratos de monjas coronadas, por mucha devoción que la futura monja le profesara, pues siempre sobre el brazo derecho de la novicia porta una imagen del Niño Jesús, ricamente ataviado, evocando al Divino Esposo, como se le conoce en el lenguaje de las clausuras conventuales.

La otra faceta, quizás no muy frecuente en el campo de la plástica pictórica, es la decoración de los tubos de los órganos. Normalmente, los que conforman el frontal de la caja del órgano, que al ser los que ofrecen más superficie permiten decorarlos con ángeles músicos, rostros de niños u otros personajes jocosos y burlescos, de cuya boca salen letras de canciones, notas musicales, etc. Esta práctica exige unos conocimientos técnicos especiales al tratarse de una superficie dura y nada absorbente, mas, Juan de Villalobos la dominaría con gran soltura, pues sabemos que engalanó algunos órganos, que incluso han llegado a la actualidad, en iglesias parroquiales de localidades de los vecinos estados de Puebla-Tlaxcala ${ }^{23}$.

Fecha de recepción: 5 de enero de 2017

Fecha de aceptación: 20 de enero de 2017

${ }^{23}$ GASTELlOU, Josué y MAULEÓN RODRÍGUEZ, Gustavo: Catálogo de órganos tubulares históricos del estado de Tlaxcala. Puebla-México, 1999. También nos brinda numerosos datos biográficos, unos ya conocidos de antemano, otros totalmente nuevos. 


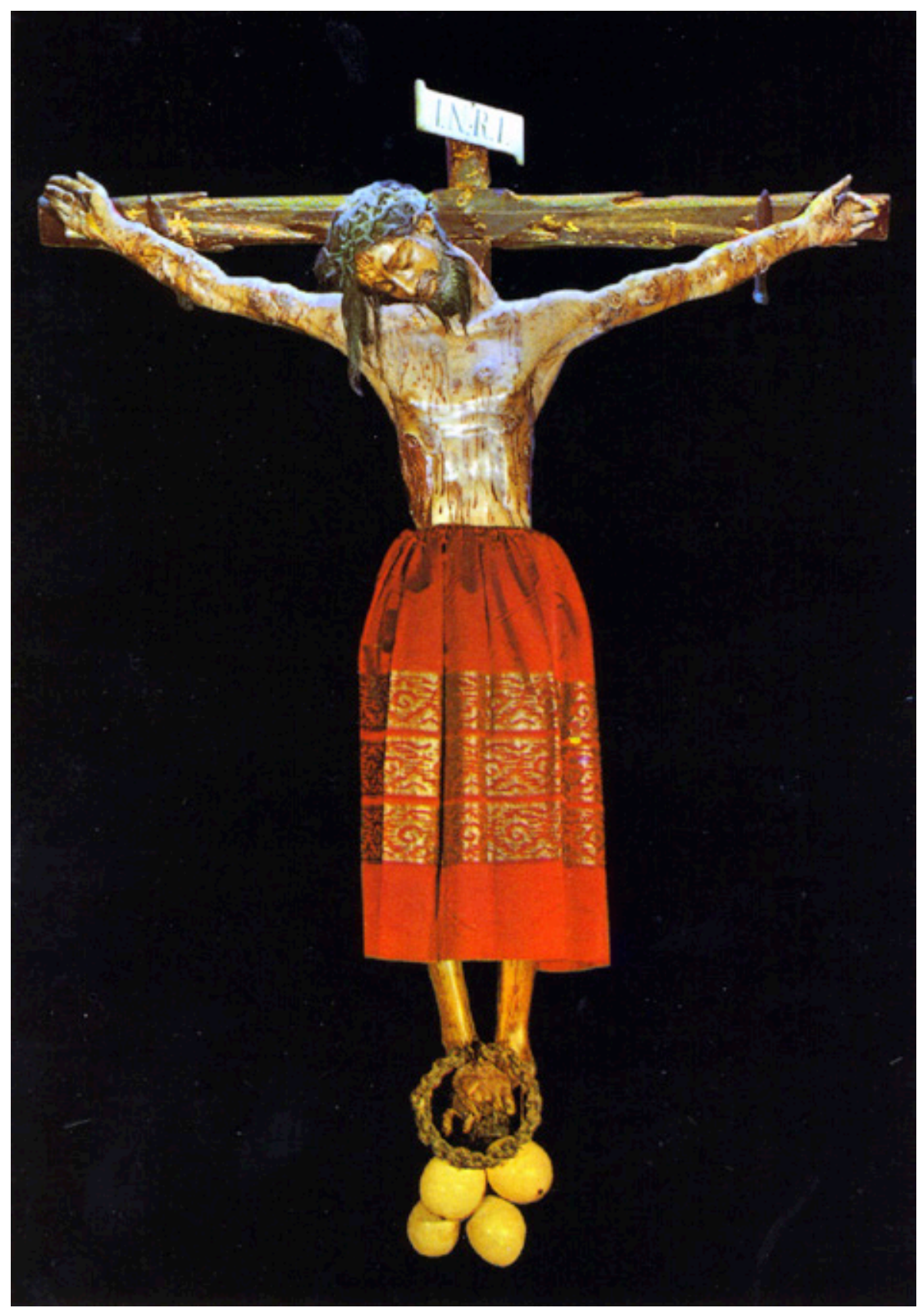

Figura 1. Cristo de Burgos o de San Agustín, catedral de Burgos.

LABORATORIO DE ARTE 29 (2017), pp. 413-434, ISSN 1130-5762 e-ISSN 2253-8305 - DOI http://dx.doi.org/10.12795/LA.2017.i29.22 
Figura 2. Cristo de Burgos o de San Agustín (detalle), catedral de Burgos.

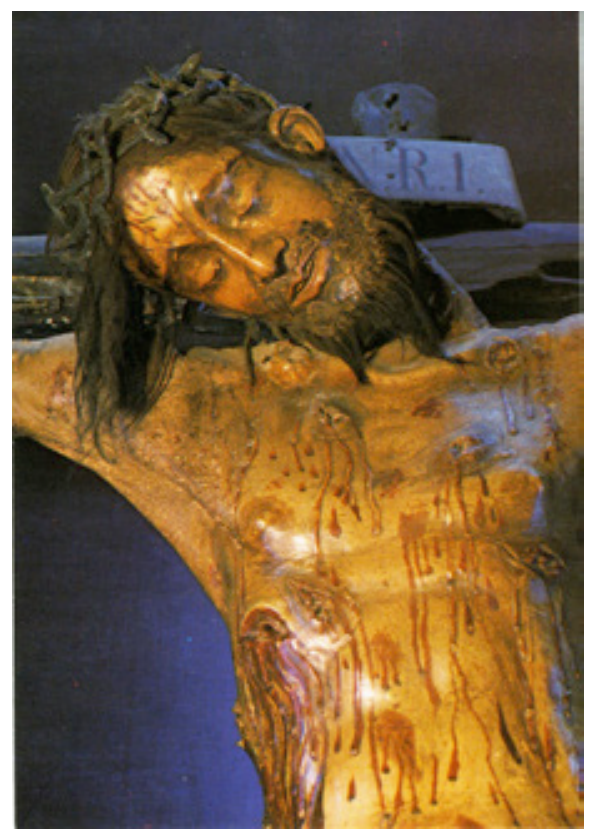

Figura 3. Cristo de Burgos o de la Trinidad, parroquia de San Gil, Burgos.

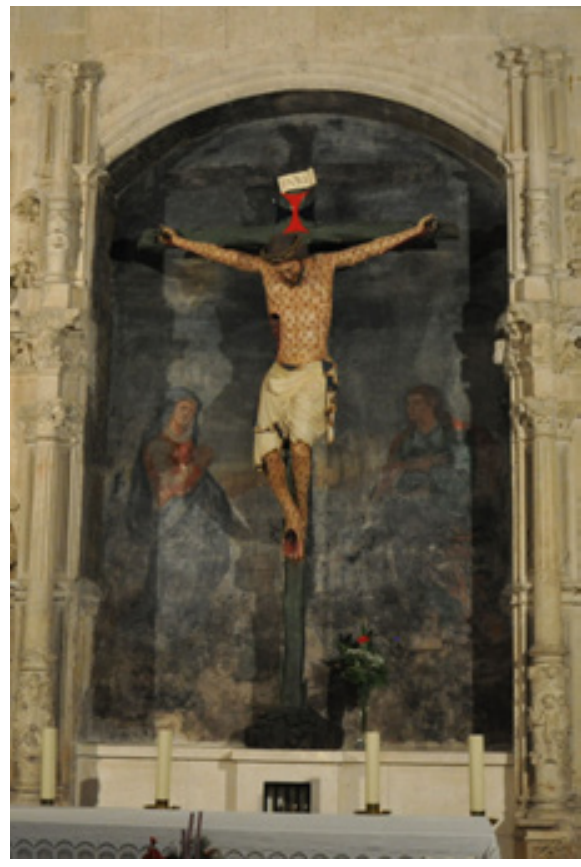

LABORATORIO DE ARTE 29 (2017), pp. 413-434, ISSN 1130-5762 e-ISSN 2253-8305 - DOI http://dx.doi.org/10.12795/LA.2017.i29.22 


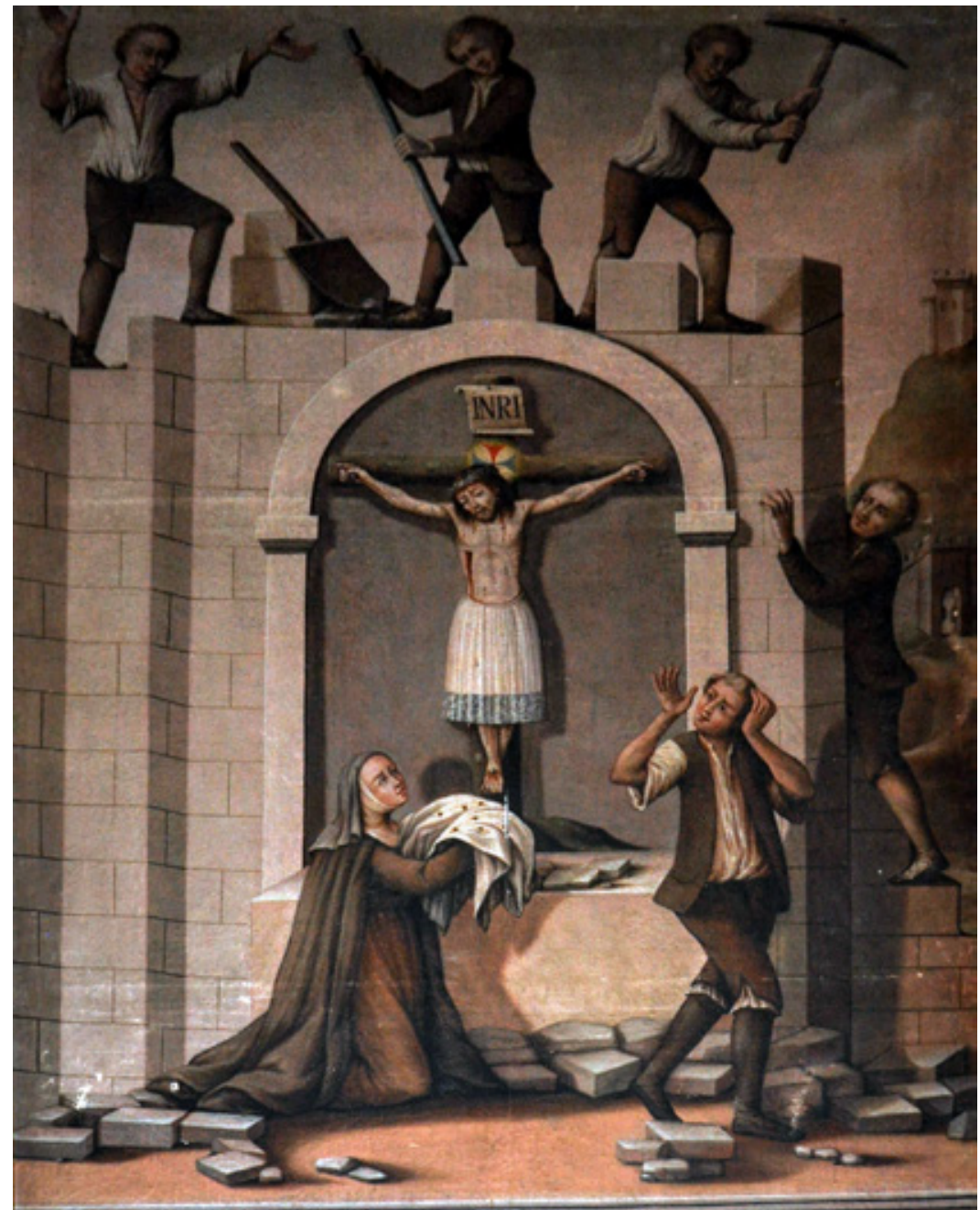

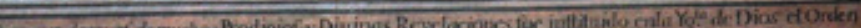
Desir ci afio \& If

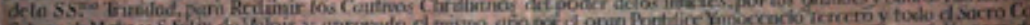

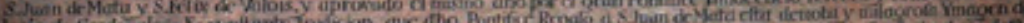

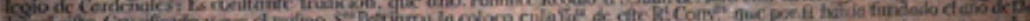
xzen a

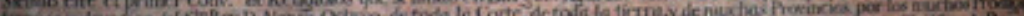

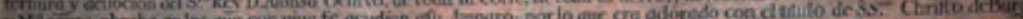

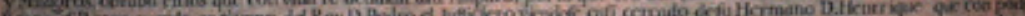

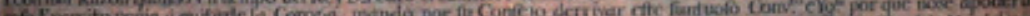

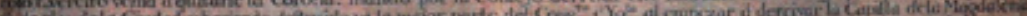

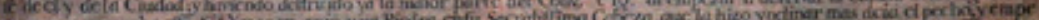

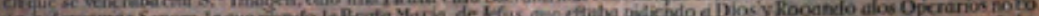

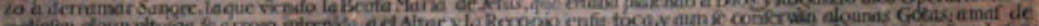

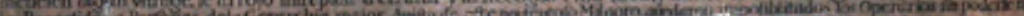

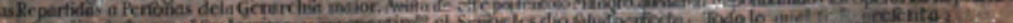

Figura 4. Cristo de Burgos o de la Trinidad, pintura alusiva al suceso de las Santas Gotas, parroquia de San Gil, Burgos. Foto: C. Becerril Rodrigo. 


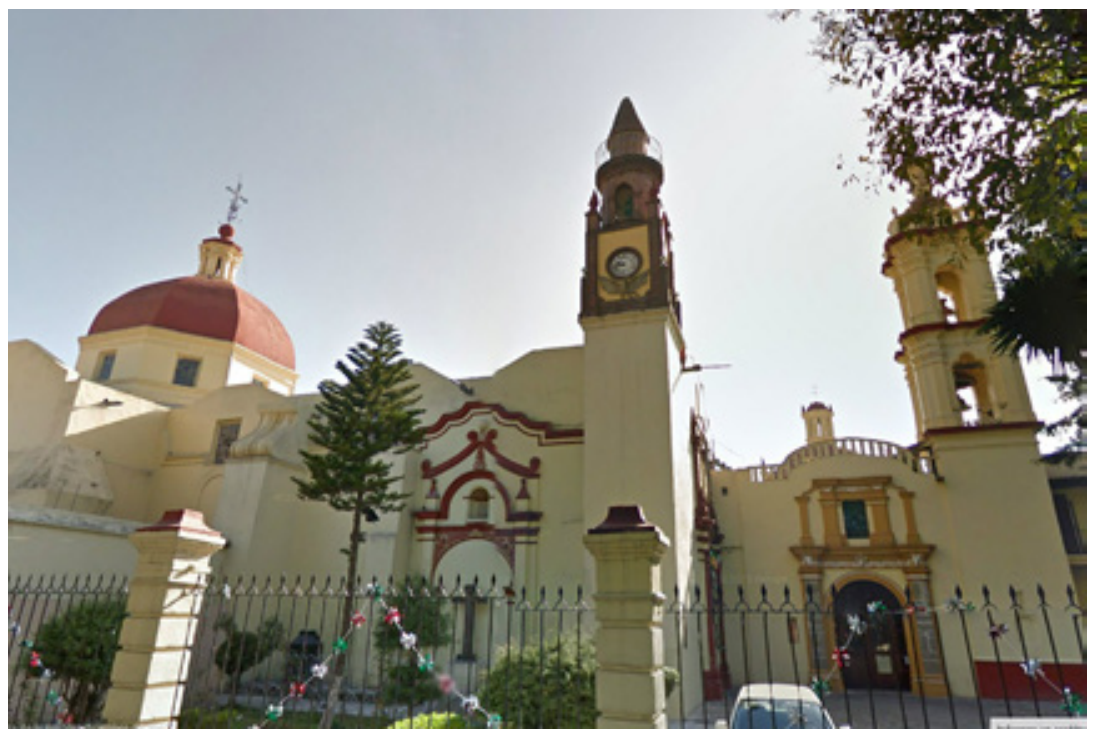

Figura 5. Conjunto parroquial de San Pablo de Apetatitlán (Tlaxcala).

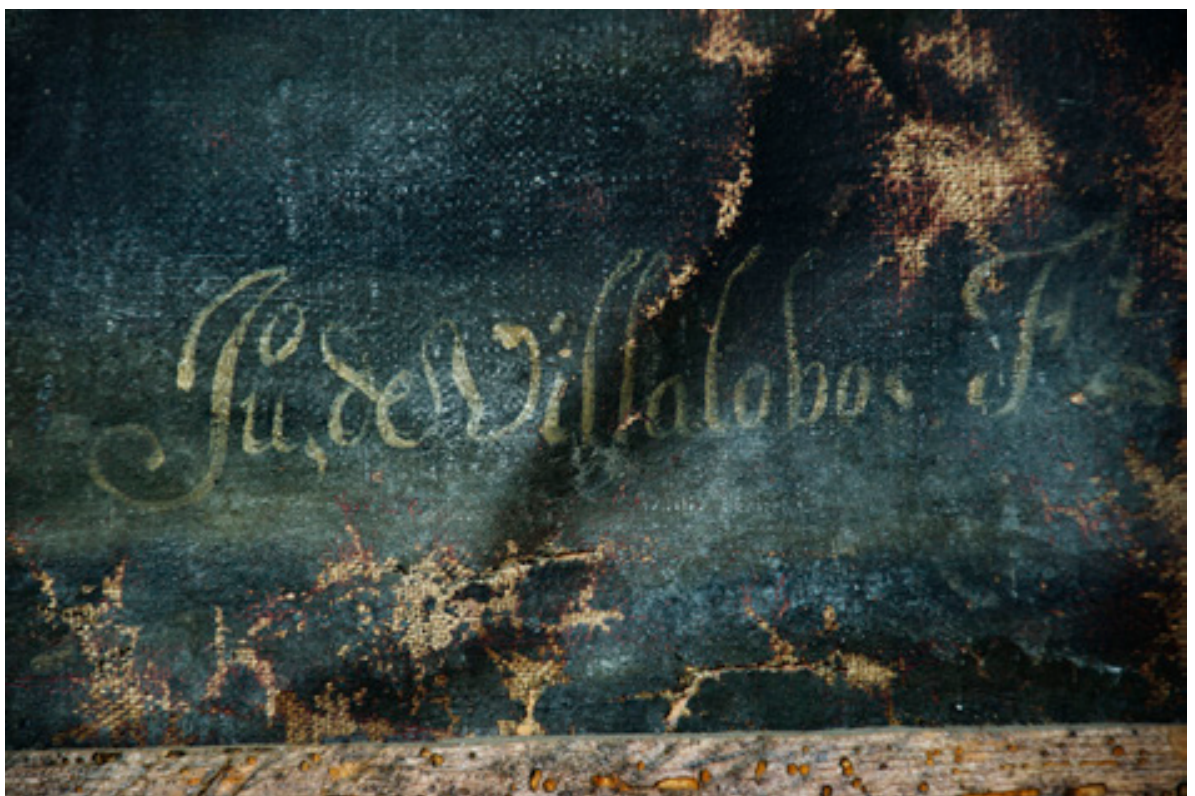

Figura 6. Juan de Villalobos, Cristo de Burgos (detalle de la firma de Juan de Villalobos), San Pablo de Apetatitlán (Tlaxcala). Foto: L. Gila Medina. 


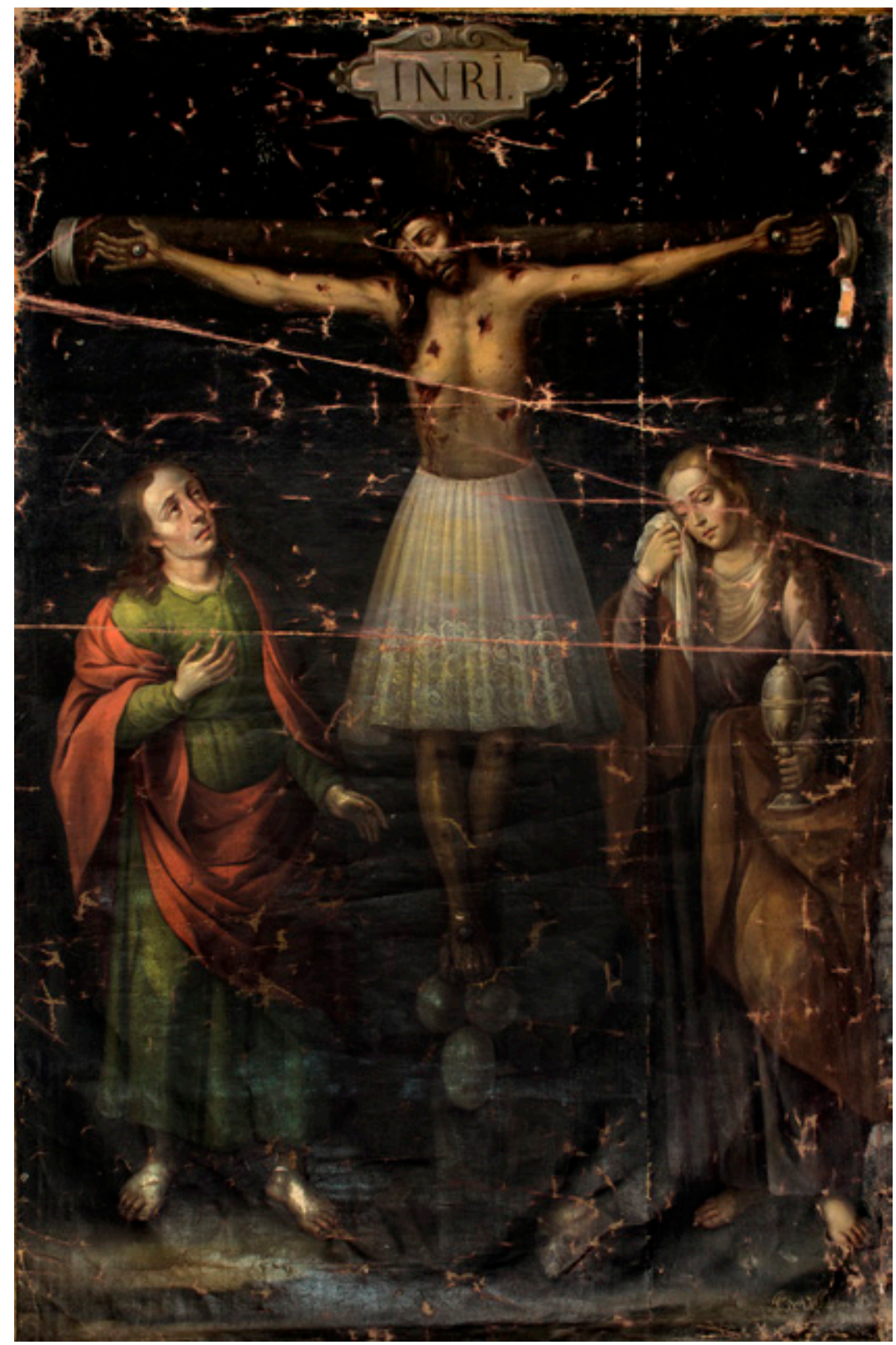

Figura 7. Juan de Villalobos, Cristo de Burgos, San Pablo de Apetatitlán (Tlaxcala). Foto: L. J. Cuesta Hernández. 


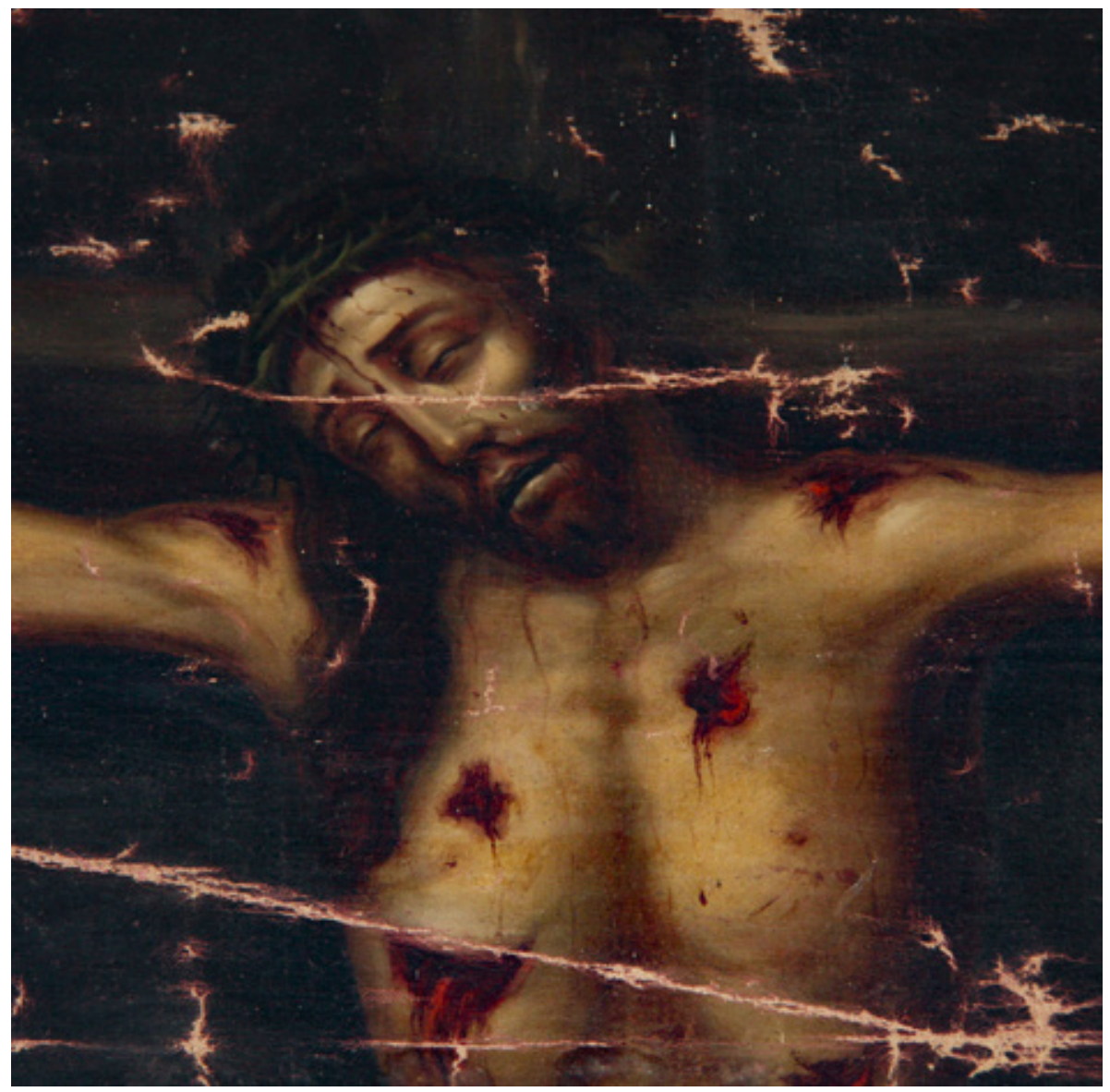

Figura 8. Juan de Villalobos, Cristo de Burgos (detalle), San Pablo de Apetatitlán (Tlaxcala). 


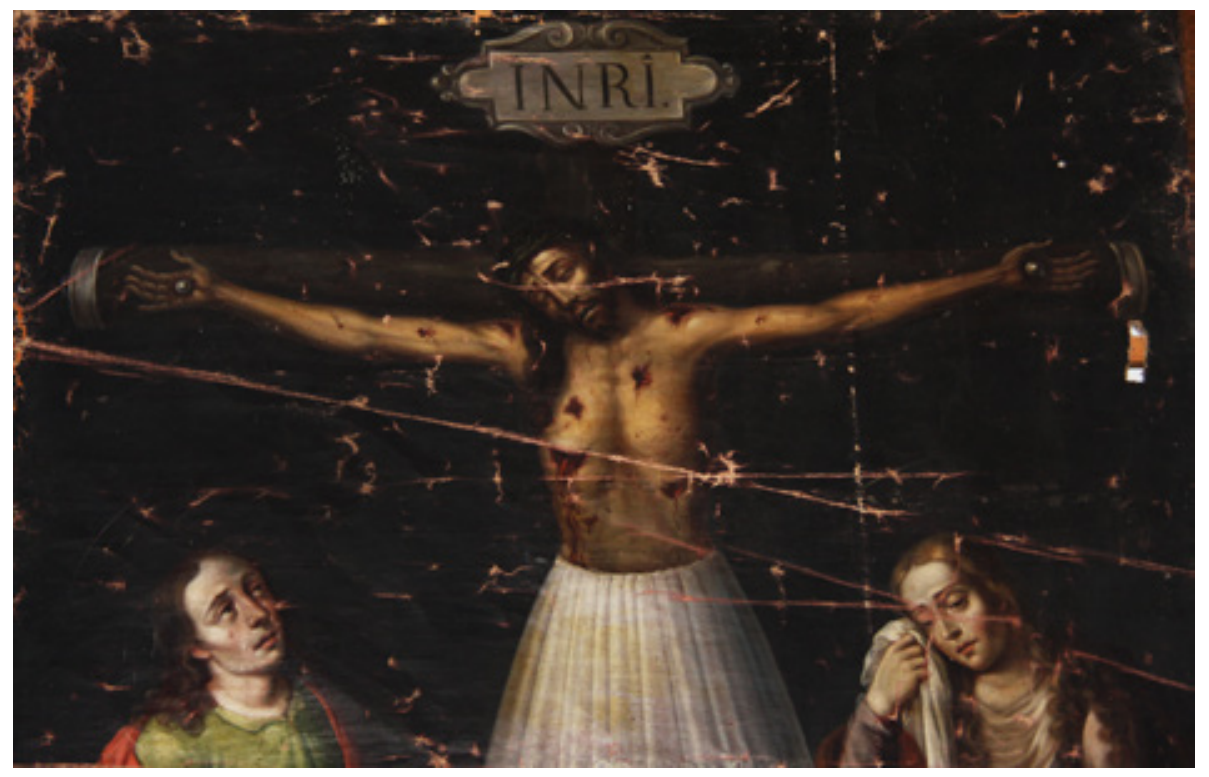

Figura 9. Juan de Villalobos, Cristo de Burgos (detalle), San Pablo de Apetatitlán (Tlaxcala). 